\title{
ENZIMAS FÚNGICAS EM DIETAS COM ALIMENTOS ALTERNATIVOS PARA FRANGOS DE CRESCIMENTO LENTO
}

Fungal enzymes in diets with alternative foods for slow-growing chicken

Las enzimas fúngicas en las dietas con alimentos alternativos para los pollos de crecimiento lento

\section{Carla Fonseca Alves Campos*1, Kênia Ferreira Rodriguês ${ }^{2}$, Roberta Gomes Marçal Vieira} $\mathrm{Vaz}^{2}$, Giovana Cristina Giannes ${ }^{3}$, Gerson Fausto da Silva ${ }^{2}$, Iberê Pereira Parente ${ }^{4}$, Aline Ferreira Amorim ${ }^{1}$, Aleane Francisca Cordeiro Barbosa1, Mônica Calixto da Silva ${ }^{1}$, Flávia Luzia Rodrigues Fonseca ${ }^{1}$, Caroliny Costa Araújo ${ }^{1}$, Valquíria Sousa Silva ${ }^{1}$, Jefferson Rodrigues da Silva ${ }^{1}$, Ecione Martins Silva ${ }^{5}$, Márcio Luz Campos ${ }^{5}$, Shayanne Batista Machado $^{5}$

${ }^{1}$ Pós-graduandos em Ciência Animal Tropical, Universidade Federal do Tocantins, Araguaína-TO, Brasil.

${ }^{2}$ Professores do Curso de Graduação em Zootecnia, Universidade Federal do Tocantins, Araguaína-TO, Brasil.

${ }^{3}$ Professora do Centro de Ciências Biológicas e da Saúde, Universidade Federal do Mato Grosso do Sul, Campo Grande/MS, Brasil.

${ }^{4}$ Professor do Instituto Federal de Educação, Ciência e Tecnologia do Maranhão, Presidente Dutra-MA, Brasil.

${ }^{5}$ Acadêmicos da Universidade Federal do Tocantins, Araguaína-TO, Brasil.

*Correspondência: Pós-graduação em Ciência Animal Tropical, Universidade Federal do Tocantins, Escola de Medicina Veterinária e Zootecnia, Zona Rural, Br 153, Araguaína, Tocantins, Brasil. CEP:77800-000. E-mail carlafazoo@hotmail.com

\section{RESUMO}

Objetivou-se nesta revisão abordar sobre enzimas fúngicas e seus efeitos em dietas com alimentos alternativos para frangos de crescimento lento. A alimentação representa maior parte do custo total de produção e para reduzir os gastos e aumentar o lucro do produtor têm sido pesquisados alimentos alternativos, como a torta de babaçu, a torta de dendê e o bagaço de mandioca, que demonstram potencial de utilização na alimentação de frangos caipira, no entanto, com limitações de uso, devido aos diferentes teores de fibra. Os polissacarídeos não amiláceos dificultam o acesso das enzimas digestíveis sobre o alimento, diminuindo a digestibilidade dos nutrientes. Para minimizar esse efeito, têm sido suplementados enzimas exógenas nas dietas das aves. Várias fontes podem originar esses aditivos, sendo a maioria adquirida por meio dos processos fermentativos. A temperatura, o $\mathrm{pH}$, a concentração do substrato e a composição dos ingredientes são fatores que influenciam a ação enzimática e, consequentemente, a disponibilidade dos nutrientes. Estudos demonstram que o uso das enzimas fúngicas podem aumentar o valor nutricional do alimento e melhorar a digestibilidade dos nutrientes, refletindo na eficiência produtiva, representando economia no custo de produção e benefícios ao meio ambiente. No entanto, novos estudos com enzimas e alimentos alternativos devem ser realizados para melhor avaliar seus efeitos na nutrição das aves.

Palavras-chave: Aditivos zootécnicos; Atividade enzimática; Polissacarídeos não amiláceos.

\section{ABSTRACT}

The feeding represents most of the total cost of production and to reduce costs and increase the profit of the producer have been researched alternative food, as the pie of babassu palm, the pie of palm and the cassava bagasse, which show potential for use in feeding the chickens for slow growth, however, with limited use, due to the different grades of fiber. Non-starch polysaccharides make it difficult for digestible enzymes to reach the food, reducing the digestibility of nutrients. To minimize this effect, exogenous enzymes have been supplemented in 
poultry diets. Various sources can originate these additives, most of which are acquired through fermentation processes. The temperature, $\mathrm{pH}$, substrate concentration and composition of the ingredients are factors that influence the enzymatic action and consequently the availability of the nutrients. Studies show that the use of fungal enzymes can increase the nutritional value of the food and improves the digestibility of nutrients, reflecting the productive efficiency, representing savings in production costs and benefits to the environment, however, it is necessary to evaluate the use in diets with alternative foods of Regional expression.

Keywords: Zootechnical additives; Enzymatic activity; Non-starch polysaccharides.

\section{RESUMEN}

Su objetivo era abordar en esta revisión sobre las enzimas fúngicas y sus efectos sobre las dietas con alimentos alternativos para los pollos de crecimiento lento. La alimentación representa la mayor parte del coste total de la producción y reducir los costes y aumentar lucre del productor se han investigado alimento alternativo, tal como la torta de babasú, la torta de palmiste y bagazo de yuca, que demuestra el potencial para su uso em la alimentación pollos cateto, sin embargo, conun uso limitado debido a los diferentes contenidos de fibra. Polisacáridos no amiláceos dificultan el acceso de las enzimas digestible acerca de los alimentos, lo que reduce la digestibilidad de los nutrientes. Para minimizar este efecto, se han complementado enzimas exógenas em las dietas de las aves. Varias fuentes pueden originate a estos aditivos, la mayoría adquirida através de los procesos de fermentación. La temperatura, $\mathrm{pH}$, concentración de sustrato y la composición de los ingredientes son factores que afectan a la actividad enzimática y, por consiguiente, la disponibilidad de nutrientes. Los estudios demuestran que el uso de enzimas de fúngicas puede aumentar el valor nutritivo de los alimentos y mejorar la digestibilidad de los nutrientes, lo que refleja la eficiência productiva, lo que representa un ahorro en los costes de producción y beneficios para el medio ambiente, sin embargo, es necessário evaluarel uso de dietas con alimento alternativo expresión regional.

Descriptores: Aditivos zootécnicos; La actividad enzimática; Polisacáridos no amiláceos.

\section{INTRODUÇÃO}

O milho e o farelo de soja são os ingredientes vegetais mais utilizados nas dietas das aves, devido aos seus valores nutricionais e a disponibilidade no mercado. A alimentação representa maior parte do custo total de produção, em consequência da elevada demanda desses alimentos, que tornam a produção susceptível a variações dos preços impostos pelo mercado e pelas diferentes regiões do país (Santos e Granjeiro, 2012). Dessa maneira, busca-se identificar produtos alternativos que possam ser utilizados no programa de alimentação das aves.

Os coprodutos agroindustriais representam alternativa viável, tanto no enfoque nutricional como econômico (Silva et al., 2007). Estudos vêm sendo desenvolvidos com matéria prima de baixo custo que possuem potencialidade para substituir os alimentos proteicos e energéticos das dietas. Nesse contexto, a torta de babaçu, a torta de dendê e o bagaço de mandioca demonstraram potencial de utilização na alimentação de frangos de crescimento lento, nos níveis de 8 a 32\% em diferentes idades, porém com limitação de uso, devido os diferentes teores de fibra e a interferência sobre a digestibilidade dos nutrientes (Silva, 2009; Silva, 2011; Oliveira, 2012).

Os polissacarídeos não amiláceos favorecem a formação de complexos que impedem o acesso das enzimas digestíveis sobre o alimento, como a formação de géis, diminuindo a digestibilidade, o tempo de permanência e viscosidade no trato gastrointestinal, afetando a absorção dos nutrientes e causando prejuízo no desempenho zootécnico das aves. Uma das formas de minimizar este efeito tem sido o uso de enzimas exógenas nas dietas (Brito et al., 2008).

As enzimas são eficientes catalisadores biológicos e seu emprego possibilita melhorar a digestibilidade dos nutrientes, o que favorece o aproveitamento do fósforo, cálcio, aminoácidos e energia, refletindo na melhor eficiência produtiva, 
representando economia no custo final da alimentação e benefícios ao meio ambiente (Barbosa et al., 2014).

Os microrganismos são produtores de enzimas que promovem a degradação dos resíduos agrícolas, tais como, celulases, xilanases, $\beta$ glicosidases, lacases e peroxidases. As atividades enzimáticas podem ser influenciadas por fatores como o pré-tratamento do alimento, $\mathrm{pH}$ e comprimento do trato gastrointestinal, o grau de hidratação e temperatura do corpo do animal, susceptibilidade da enzima exógena ao ataque das enzimas endógenas, concentração do produto em razão da hidrólise da enzima, atividade e concentração das enzimas endógenas e os tipos de ingredientes utilizados nas dietas (Acomovic e Mccleary, 1996).

Resultados de pesquisa têm demonstrado que o uso de enzimas exogénas melhoram o aproveitamento da proteína (Selle et al., 2010; Zhang et al., 2014), da energia (Stefanello et al., 2016; Valadares et al., 2016), dos polissacarídeos não amiláceos (Zhang et al., 2014) e do fósforo (Cardoso Junior et al., 2010; Pereira et al., 2010; Pereira et al., 2012) das dietas de aves, contribuindo para minimizar a poluição ambiental (Lima et al., 2007). Autores relataram ainda, que o ganho de peso e conversão alimentar foi melhor com uso dos complexos (Nunes et al., 2015), com aumento no rendimento de peito e asas de frangos de corte (Dalólio et al., 2016).

Dentro dessa perspectiva e considerando a relevância nutricional do uso das enzimas exógenas nas dietas de aves, objetivou-se com esta revisão abordar sobre enzimas fúngicas e seus efeitos em dietas com alimentos alternativos para frangos de crescimento lento.

\subsection{ALIMENTOS ALTERNATIVOS}

Na produção de frangos de crescimento lento um dos entraves é a disponibilidade de matéria prima para a confecção de rações, além do custo com a alimentação, que representa em média $70 \%$ do custo total de produção (Santos e Granjeiro, 2012). Buscase então, identificar alimentos alternativos de expressão regional com potencialidades e restrições de uso nas diferentes fases de produção (Bellaver, 2001).

\subsubsection{Farinha do mesocarpo do babaçu e a torta de babaçu}

O babaçu (Palmaeorbignyamartiana) é uma palmácea nativa, principalmente nos estados do Maranhão, Piauí e Tocantins. A farinha do mesocarpo e a torta do babaçu são os coprodutos obtidos do processamento dos cocos (Albieroet al., 2007), que ao chegarem na indústria, seguem para máquinas quebradoras onde ocorre a pelagem e liberação do epicarpo, posteriormente, são conduzidos para peneiras onde é liberado o mesocarpo e ao ser moído dar origem a três tipos de farinha: farinha orgânica, farinha média e farinha amilácea fina. $\mathrm{O}$ endocarpo junto com a amêndoa é serrado e são separados. A amêndoa é lavada, pesada e moída para facilitar o cozimento e a prensagem. Após o cozimento, a amêndoa é prensada para a extração do óleo restando a torta de babaçu (Santos Neta, 2010).

A torta de babaçu tem alto teor proteico e a farinha do mesocarpo do babaçu tem baixa proteína bruta e elevado conteúdo de energia (Carneiro et al., 2013).

\subsubsection{Torta de dendê}

\section{REVISÃO DE LITERATURA}


A torta de dendê é o produto resultante da extração do óleo da amêndoa do dendê (Elaeis guineenses). As amêndoas da extração do óleo de palma seguem para retirada das fibras, posteriormente são secas, trituradas, submetidas ao vapor de água e prensadas. O óleo obtido é filtrado e decantado, finalizando, com o resíduo da prensagem, a torta, que possui $16,01 \%$ de proteína bruta (PB), 14,95\% de fibra bruta (FB) e $2009 \quad \mathrm{kcal} / \mathrm{kg}$ de energia metabolizável (EM) (Silva, 2009).

\subsubsection{Bagaço de Mandioca}

A mandioca (ManihotesculentaCrantz) é uma planta arbustiva que atinge até $3 \mathrm{~m}$ de altura e pode gerar vários resíduos por meio do seu processamento.
O bagaço de mandioca é o resíduo da extração da fécula de baixo valor comercial (Fiorda et al., 2013). Inicialmente, a raiz de mandioca é descascada, triturada e lavada para retirar o amido, resultando em resíduo fibroso e grosseiro, que apresenta $88 \%$ de MS, 1,26\% de PB e 2465 kcal de EM (Oliveira, 2012).

\subsection{ALIMENTOS ALTERNATIVOS NA}

\section{ALIMENTAÇÃO DE AVES}

Resultados experimentais demonstraram possibilidades de uso destes ingredientes nas dietas das aves, mas, com influência negativa de elevados teores de fibra presente na composição química (Quadro 1).

Quadro 1. Pesquisas desenvolvidas e resultados obtidos com o uso de alimentos alternativos para frangos de crescimento lento

\begin{tabular}{|l|l|l|}
\hline \multicolumn{1}{|c|}{ AUTORES } & \multicolumn{1}{c|}{$\begin{array}{c}\text { ALIMENTOS } \\
\text { ALTERNATIVOS }\end{array}$} & \multicolumn{1}{c|}{ RESULTADOS } \\
\hline Silva (2009) & Torta de babaçu & $\begin{array}{l}\text { A Energia metabolizável aparente (EMA) e energia metabolizável aparente } \\
\text { corrigida para balanço de nitrogênio (EMAn) foram de } 2650 \text { e } 2580 \mathrm{Kcal} / \mathrm{kg}, \\
\text { respectivamente. Recomendou-se níveis de } 8 \% \text { até } 28 \text { dias de idade, com cautela } \\
\text { devido ao alto teor de fibra, de 29,50\% e até 32\% em dietas dos } 35 \text { aos } 84 \text { dias. }\end{array}$ \\
\hline Silva (2011) & Torta de dendê & $\begin{array}{l}\text { Os valores de EMA e EMAn foram: 2009 e 1840 kcal/kg, respectivamente. O } \\
\text { alimento tem 16\% de fibra bruta e recomendou-se o nível de } 12 \% \text { para a fase } \\
\text { inicial e crescimento. }\end{array}$ \\
\hline $\begin{array}{l}\text { Oliveira (2012) } \\
\text { Holanda et al. } \\
\text { (2015) }\end{array}$ & $\begin{array}{l}\text { Fagaço de mandioca } \\
\text { integral }\end{array}$ & $\begin{array}{l}\text { Recomendou-se níveis de 10\% na fase inicial, não recomendando a utilização de } \\
31 \text { a } 60 \text { dias, devido ao alto teor de fibra do alimento, mas pode ser utilizada até } \\
30 \% \text { na fase final. }\end{array}$ \\
\hline
\end{tabular}




\section{OS POLISSACARÍDEOS NÃO AMILÁCEOS (PNAS)}

Os PNA's são componentes da parede celular e compõem mais de $90 \%$ dessa estrutura, é heterogêneo de polissacarídeos e compreendem ampla classe, como celulose, hemicelulose, pentosanas, $\beta$ glucanas, xilose, quitina e pectinas, oligossacarídeos como a rafinose (trissacarídeo) e a estaquiose (tetrassacarídeo) e não podem ser digeridos por animais monogástricos, pois, não possuem enzimas capazes de quebrar as ligações resistentes a hidrólise (Brito et al., 2008).

São polímeros de açúcares simples que estão unidos por ligações glicosídicas, com diferentes graus de solubilidade em água, tamanho e estrutura (Căpriță et al.,2010), essencialmente, compostos por fibras não digestíveis, que pouco adiciona valor nutritivo aos alimentos.

Os PNA's dependendo da solubilidade dos seus constituintes com a água, podem ser classificados, em solúveis e insolúveis. As fibras solúveis compostas principalmente pela hemicelulose (arabinoxilanos, $\beta$-glucanas), no lúmen intestinal, promovem aumento da viscosidade da digesta devido estas absorverem grandes quantidades de água, formando substância gelatinosa (Conte et al., 2003), que age como barreira entre enzima e substrato e os produtos da digestão, e modificam a secreção endógena de água, proteínas, eletrólitos e lipídeos (Mourinho, 2006) (Figura 1).

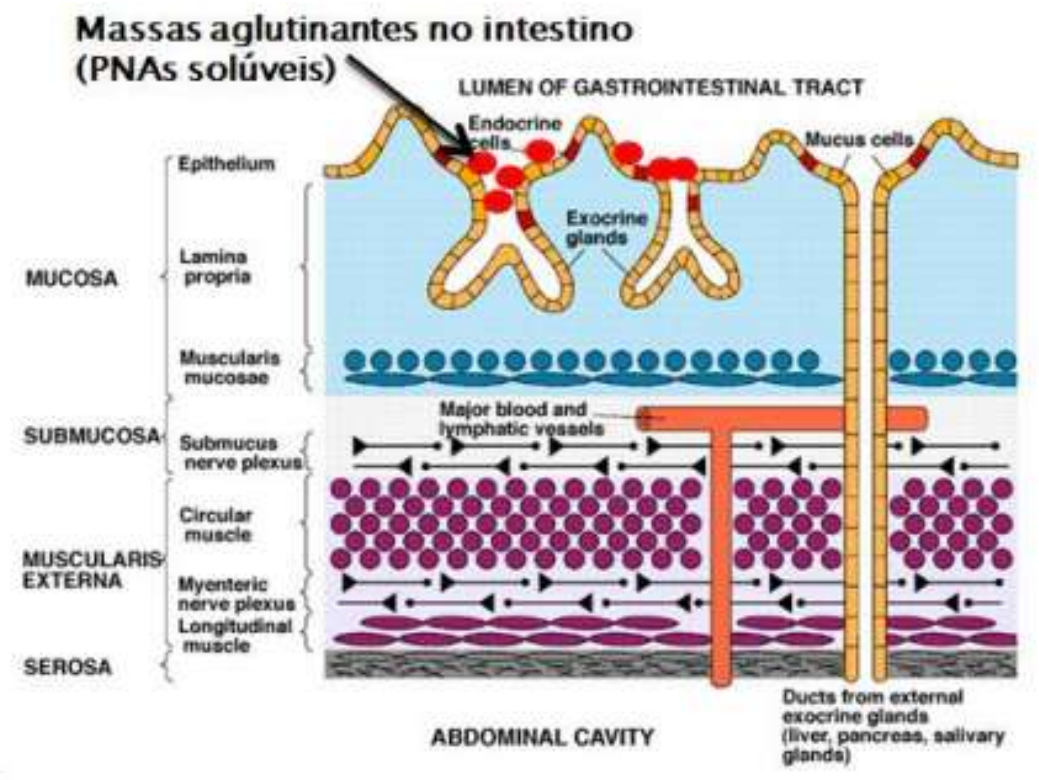

Figura 1. Polissacarídeos não-amiláceos obstruindo as microvilosidades intestinais. Fonte: Adaptada de Vander et al., (2000).

À medida que a viscosidade da digesta aumenta, a taxa de difusão diminui e pode reduzir a energia do alimento, com decréscimo na digestibilidade dos nutrientes, ao modificarem o tempo de permanência no trato digestivo (Brito et al., 2008).

Baixa concentração de oxigênio e aumento das fermentações microbianas no intestino delgado, 
podem ocorrer devido ao aumento do tempo de permanência do conteúdo digestivo, com desenvolvimento da flora anaeróbia (Choct, 1997), que concorrem pelos nutrientes com as aves, reduzindo a eficiência da utilização, além de permitir a produção de toxinas e a desconjugação dos sais biliares, eficazes na digestão dos lipídeos (Mendes, 2015).

Para determinar a fração fibrosa dos alimentos vários métodos têm sido utilizados, fibra bruta e as fibras em detergente ácido (FDA) e detergente neutro (FDN) (Silva e Queiroz, 2006), sendo o FDN uma medida importante para a caracterização da fibra das rações para aves (Jeraci e Van Soest, 1990), todavia, pesquisadores ainda utilizam os valores da fibra bruta.

As PNA's são encontradas em sementes de oleaginosas, como a soja e a canola, os grãos de cereais, com os seus respectivos coprodutos, tais como os farelos de arroz e de trigo, na cevada e aveia, como $\beta$-glucanos, no trigo, triticale e centeio, como pentosanas, as arabinoxilanas (Campestrini et al., 2005).

A torta de babaçu, a farinha do mesocarpo de babaçu, a torta de dendê e o bagaço de mandioca são coprodutos em abundância na região amazônica e com potencial de uso para aves, porém, apresentam elevados teores de fibra (Oliveira, 2012; Silva, 2009; Silva, 2011). Dessa forma, deve-se buscar maior aproveitamento dos seus nutrientes e uma alternativa seria o uso de enzimas nas dietas.

\section{ENZIMAS}

As enzimas exógenas são aditivos zootécnicos digestivos (Brasil, 2004), proteínas globulares de estrutura terciária ou quaternária que atuam como catalisadoras dos processos biológicos, não tem função nutricional direta, mas, auxiliam o processo digestivo, aumentando a velocidade das reações bioquímicas, sem serem consumidas no processo (Campestrini et al., 2005; Pessoa, 2010).

No modo de ação, as enzimas têm sítio ativo que contém aminoácidos, cujas cadeias laterais, conferem estrutura espacial adequada para ligar-se ao substrato específico, formando complexo de enzimasubstrato que permanece ativo por longos períodos, permitindo que atuem na ruptura de determinada ligação química (Nelson e Cox, 2014).

A International Union ofBiochemistryand Molecular Biology (IUBMB) classificou as enzimas em seis classes, de acordo com o tipo de reação que catalisam, em: oxidorredutases, transferases, hidrolases, liases, isomerases e ligases, todavia, utilizam-se as enzimas hidrolases na nutrição animal, como fosfatases, glicosidases e proteases (Dourado et al., 2014).

As enzimas exógenas são preconizadas para complementar a ação das enzimas endógenas (proteases, amilases e fitases), ou de forma aditiva, para suplementar as não sintetizadas ou sintetizadas em quantidades insuficientes pelo organismo dos animais ( $\beta$-glucanases, pentosanas, e $\alpha$-galactosidases) (Campestrini et al., 2005; Polycarpo, 2011).

Fontes de animais, vegetais e microbianas, como fungos, bactérias e leveduras podem originar as enzimas, sendo a maioria adquirida por meio dos processos fermentativos (Gerhardt, 2013; Kilikian e Pessoa jr, 2001), devido principalmente, as condições para aquisição, que podem ser controladas para atender o mercado, a diversidade de ser obtida pelos micro-organismos, o maior rendimento, e às complexidades operacionais e econômicas de extração de tecido vegetal e animal (Lopes, 2010; Minafra, 2007). 


\subsection{FATORES QUE INTERFEREM NA ATIVIDADE ENZIMÁTICA}

As características da enzima (temperatura, $\mathrm{pH}$ e estabilidade) e a composição dos ingredientes são fatores que influenciam os efeitos da adição de enzimas à alimentação animal (Peixoto-nogueira et al., 2013), na velocidade da ação enzimática e, consequentemente, a disponibilidade de nutrientes. Por esse motivo, nota-se o receio de que as enzimas possam conservar nível de atividade satisfatória para alcançar reposta expressiva (Gerhardt, 2013).

\subsubsection{Temperatura}

A temperatura influencia a atividade e a conservação das estruturas das biomoléculas (Gomes et al., 2007). Quando esta aumenta, a velocidade da reação inicialmente se eleva devido a energia cinética das moléculas com o substrato, sendo maior a probabilidade de choques efetivos entre elas (Minafra et al., 2007), até o pico de velocidade ser atingido. Temperaturas mais altas resultam em redução na velocidade de reação, como resultado da desnaturação da enzima (Nelson e Cox, 2014).

A temperatura acima de $50-55^{\circ} \mathrm{C}$, causa modificações estruturais, com perda do poder de catálise, sendo que a maioria das enzimas nos animais tem temperatura ótima entre 35 e $40^{\circ} \mathrm{C}$ (Marzzoco, 2007). A $\alpha$-amilase na faixa de temperatura de 30 a $70^{\circ} \mathrm{C}$ apresenta elevada atividade, tendo máximo valor em $50^{\circ} \mathrm{C}$ (Minafra, 2007), $50^{\circ} \mathrm{C}$ para a xilanasefúngica(Paz et al., 2014) e $50^{\circ} \mathrm{C}$ para a fitase (Elkhalil et al., 2007). O que é bom para sua aplicabilidade nas rações e sem perigo de desnaturação proteica no organismo das aves (Minafra, 2007).

\subsection{2 pH}

O sítio ativo das enzimas pode ser influenciado pelo $\mathrm{pH}$, já que estes são formados por grupos químicos, maior parte aminoácidos, que podem sofrer ionizações e adquirir cargas momentâneas, promover mudança conformacional, afetando o complexo de enzima-substrato e, por conseguinte, a atividade enzimática (Nelson e Cox, 2014).

$\mathrm{O}$ pH onde a distribuição de cargas elétricas das moléculas da enzima e, em especial do sítio ativo é ideal para a catálise, varia para diferentes enzimas (Minafra, 2007), sendo que pH maior ou menor, a atividade pode diminuir e extremos podem desnaturálas (Nelson e Cox, 2014).

As xilanases derivadas de distintos microrganismos tem estabilidade com $\mathrm{pH}$ na faixa de 3 a 10, sendo que, a produção enzimática ótima é entre 4 e 7 (Lopes, 2010) e para Paz et al., (2014) o pH ideal é 6,0 e já a fitase tem pH ótimo de 5,5 (Elkhalil et al., 2007).

A $\alpha$-amilase tem boa estabilidade em $\mathrm{pH} 3$ a 9, com $80 \%$ do rendimento, sendo a faixa ótima de 5,0 a 8,0, com isso a adição da enzima na ração, não têm prejuízo, pois ela será estável no $\mathrm{pH}$ da ração, que é por volta de 6 a 6,4. Além disso, a atividade da enzima misturada a ração diminui a possibilidade de desnaturação (Minafra, 2007).

\subsubsection{Concentração do substrato}

Nas reações enzimáticas, à medida que a concentração de substrato aumenta a velocidade 
inicial se eleva até atingir valor máximo e quando estabiliza, significa que a enzima foi saturada pelo substrato. Dessa forma, é necessário o conhecimento da quantidade adequada de substrato a ser utilizada para a dosagem de determinada enzima, com atividade enzimática em velocidade máxima (Nelson e Cox, 2014).

\subsection{ENZIMAS FÚNGICAS}

Os fungos filamentosos dos gêneros Aspergillus, Penicillium, Trichoderma e Rhizopus são os maiores fornecedores de enzimas industriais (Kilikian e Pessoa jr, 2001), pois permitem o uso de substratos baratos, como resíduos agrícolas e produção independente de aspectos sazonais (Gerhardt, 2013).

A escolha do microrganismo é peça chave no sucesso da produção e devem apresentar características desejáveis, tais como, elevada eficiência na conversão do substrato em produto, com acúmulo no caldo fermentado; deve ter estabilidade quanto ao comportamento fisiológico; permitir a rápida liberação do produto e não deve gerar substâncias incompatíveis, nem ser patogênico e não exigir processo complexo e meios de cultura onerosos (Kilikian e Pessoa jr, 2001).

Os meios de cultivo podem ser sintéticos e naturais e devem atender à demanda nutricional do microrganismo produtor, aos objetivos do processo e à escala de operação; deve ter baixo custo e boa disponibilidade; composição fixa e que não cause problemas na recuperação do produto e dificuldades no tratamento final dos efluentes (Kilikian e Pessoa jr, 2001).

As enzimas fúngicas são produzidas por meio de processos fermentativos rigidamente controlados e são caracterizadas por apresentarem alta produção, menor custo, maior variabilidade e estabilidade ao armazenamento em condições de $\mathrm{pH}$ e temperatura (Manifra, 2007).

Após a fermentação, as enzimas são removidas por centrifugação, filtração, precipitação fracionada, separação cromatográfica, separação por membranas, liofilização ou pela combinação desses e de outros métodos, posteriormente, são encaminhadas para etapas de purificação, até alcançar o grau necessário, que depende da aplicação final. Caldos enzimáticos impuros, ou parcialmente purificados, podem ser utilizados como catalisadores, sendo que essas etapas de purificação são responsáveis pelo maior custo dos processos biotecnológicos (Kilikian e Pessoa jr, 2001) e a recuperação na maioria das vezes é baixa (Morales et al., 1995).

Dentre as principais enzimas de uso na alimentação animal, podemos citar as amilases, xilanases, proteases, fitases,glucanases e lípases, sendo que a recomendação de uso varia de acordo com a composição dos ingredientes presentes na dieta animal (Dourado et al., 2014).

A adição das enzimas para monogástricos promovem aumento da digestibilidade dos alimentos e dos polissacarídeos não amiláceos, disponibilizando certos nutrientes para a absorção, com aumento do valor energético de ingredientes, maximizando o aproveitamento da proteína, energia e fósforo, proporcionando o emprego de alimentos com menor qualidade nutricional (Dourado et al., 2014; Pessoa, 2010).

\subsubsection{Carboidrases}

As carboidrases catalisam a quebra dos carboidratos em açúcares simples e podem ser 
classificados em enzimas que degradam o amido e os polissacarídeos não amiláceos (Fireman e Fireman, 1998). A amilase exógena completa a ação das amilases endógenas, enquanto que as enzimas que degradam os PNAs, são adicionadas nas rações devido as aves não a sintetizarem (Meneghetti, 2013).

A amilase é largamente difundida na natureza, encontradas em bactérias, fungos, plantas e animais (Minafra, 2007). O Aspergillus e Rhizopus são muito utilizadas para sua produção, mas o Aspergillus é mais tolerante a altas temperaturas e dominam o mercado (Gonçalves, 2006). A enzima atua na hidrólise das moléculas de amido, decompondo-o em amilose e amilopectina no intestino delgado, conduzindo ao aumento na utilização dos nutrientes, com consequente melhoria nas taxas de crescimento (Meneghetti, 2013).

As amilases quanto as ligações hidrolisadas podem ser agrupadas em: $\alpha$-amilase, $\beta$-amilase, glicoamilase, pululanase, isoamilase, ciclodextrinaglicosiltransferase e $\alpha$-D-glicosidase. A quebra de oligossacarídeos como rafinose e estaquiose em monossacarídeos, como glicose, galactose e frutose, é catalisada pelas galactosidases, aumentando a energia metabolizável dos alimentos (Ott, 2005).

As xilanases são glicosidades que catalisam a hidrólise dos substratos susceptíveis, principalmente a xilana, que é o principal componente da hemicelulose e o polissacarídeo mais abundante e renovável da natureza (Lopes, 2010). Os produtos dessas reações são os monômeros D-xilose e xilo-oligossacarídeos de diferentes tamanhos e de menor peso molecular (Menezes e Barreto, 2015).

A endo-1,4- $\beta$-xilanase é o nome químico da xilanase, mas, sinônimos são usualmente empregados, como, endo-xilanase, 1,4- $\beta$-D-xilana-xilanohidrolase, endo-1,4- $\beta$-D-xilanase, $\beta$-1,4-xilanase e $\beta$-xilanase
(Collins et al., 2005). São produzidas por vários microorganismos, como o Aspergillus niger, que produz xilanases extracelulares, e a Trichoderma, que gera diversos tipos (Aguiar e Menezes, 2000; Irshad et al., 2012; Santos e Ishii, 2011).

O uso na alimentação das aves promove efeito positivo sobre a degradação da camada de polissacarídeos não amiláceos (PNAs) da membrana celular, devido à redução da viscosidade da digesta (Brito et al., 2008), com liberação de nutrientes encapsulados nas estruturas da parede celular, favorecendo o contato entre tais nutrientes e enzimas endógenas (Campestrini et al., 2005), podendo o aproveitamento da fração indigestível chegar a 27 e $10 \%$ por meio da glucanase e xilanase, respectivamente (Cowieson et al., 2010).

\subsubsection{Proteases}

As aves têm capacidade de sintetizar proteases e o uso de proteases exógenas tem a finalidade de suplementar as enzimas endógenas (Pessoa, 2010).

As proteínas pouco digestíveis podem ter seu uso potencializado por meio da utilização de proteases, melhorando a sua digestão (Classen, 1996), pois o mau aproveitamento destas podem causar maior excreção de nitrogênio, que é um nutriente caro e com potencial poluidor (Fireman e Fireman, 1987) quando descartado de forma incorreta.

As proteases exógenas são hidrolases, responsáveis pela catálise das ligações peptídicas entre os aminoácidos das proteínas e sua adição inativa fatores antinutricionais presentes em determinados alimentos (Cowieson et al., 2006) e podem maximizar a disponibilidade de aminoácidos, colaborando com a energia metabolizável das rações e, por conseguinte, aprimorando o desempenho 
zootécnico dos animais e reduzindo o custo de produção (Meneghetti, 2013).

Outras potenciais ações das proteases em dietas avícolas têm sido atribuídas ao aumento da produção endógena de peptidase (Isaksen et al., 2011). É possível reduzir os níveis de aminoácidos sintéticos suplementados nas dietas de frangos de corte, considerando digestibilidade de até $40 \%$ superior a real, quando se utiliza protease, não afetando os parâmetros de desempenho, rendimento de carcaça e cortes para abates até os 42 dias de idade (Dessimoni, 2011).

\subsubsection{Fitases}

O fitato é um fator antinutricional formado pelo ácido fítico, que se liga firmemente aos íons dos minerais, $\mathrm{Na}+, \mathrm{Mg}++, \mathrm{K}+, \mathrm{Ca}++, \mathrm{Zn}++$, e pode integrar-se com íons positivos de proteínas, aminoácidos (lisina, e arginina), carboidratos, lipídios, diminuindo sua solubilidade e digestibilidade, e enzimas como tripsina e outras proteases, diminuindo sua atividade (Kornegay, 2001).

O fósforo na molécula de fitato é indisponível, sendo a principal fonte de armazenamento em material vegetal. A fitase forma um grupo de enzimas que clivam a molécula de ácido fítico para liberar fósforo e cálcio, bem como, minerais e aminoácidos, que serão melhores digeridos e absorvidos pelas aves, promovendo, consequentemente, maior aproveitamento da energia, além de melhorar a atividade das enzimas endógenas (Fireman e Fireman, 1998). Quimicamente são definidas como fosfatases mio-inositol e podem ser classificadas em ácidas, neutras ou alcalinas, conforme o $\mathrm{pH}$ ótimo da atividade enzimática (Sousa, 2013).
Muitas espécies de bactérias, fungos e leveduras, produzem a enzima fitase, sendo o Aspergillus, o mais importante para a produção em escala comercial. A enzima é utilizada com intuito de suplementar a alimentação de aves e suínos (Campestrini et al., 2005).

Resultados de pesquisa têm demonstrado que o aproveitamento do fósforo fítico pode ser melhorado com a utilização de enzimas exógenas (Cardoso Junior et al., 2010; Pereira et al., 2012; Pereira et al., 2010), liberando outros nutrientes além do fósforo e outros minerais. Autores descreveram ainda, a redução na excreção de nitrogênio, cálcio, fósforo, energia e de proteína, com uso de fitase (Gomide et al., 2011a; Gomide et al., 2011b; Vasconcellos et al., 2011). Dessa forma, nota-se que a suplementação dessa enzima possibilita a redução do uso de aminoácidos essenciais como lisina, metionina e treonina (Sousa, 2013), fósforo inorgânico e energia, nas dietas, contribuindo para minimizar a poluição ambiental (Lima et al., 2007).

\subsubsection{Lipases}

As lipases são um grupo de enzimas responsáveis por catalisar a síntese e hidrólise de triacilgliceróis, em ácidos graxos livres, monoacilgliceróis, diacilgliceróis e glicerol (Messias et al., 2011) e podem ter variação nas propriedades catalíticas, dependendo da origem: animal (pancreática, hepática e gástrica), microbiana (bactérias e fungos) e vegetal (Martins et al., 2008). Em escala industrial, os fungos são empregados como produtores industriais de lipases, normalmente no meio extracelular, o que facilita a extração do meio fermentado, porém apresenta elevados custos de produção (Messias et al., 2011). 


\section{ENZIMAS NAS DIETAS DE AVES}

A incorporação de enzimas na dieta pode ser feita de duas maneiras: acrescentando as enzimas na ração calculada (On-Top), sem alterar os níveis nutricionais e levando-se em conta o teor nutricional propiciado pelas enzimas, modificando a formulação das dietas, visando o mesmo desempenho de uma ração com os níveis nutricionais recomendados (Barbosa et al., 2008).

Os efeitos da protease $(0,05 \%)$ foram avaliados sobre os coeficientes de metabolizabilidade dos nutrientes em dietas contendo farinha de penas com enzima e matriz nutricional valorizada; com enzima e sem valorização; sem enzima e sem enzima com valorização, para frangos de corte de um a 32 dias. Na fase inicial, houve maior coeficiente de metabolizabilidade da proteína para as aves que consumiram ração com valorização da matriz nutricional da enzima, independentemente da adição de protease. $\mathrm{Na}$ fase final, níveis nutricionais reduzidos e enzima sem valorização melhoram os coeficientes de metabolizabilidade dos nutrientes (Matias et al., 2015).

$\mathrm{O}$ valor nutricional do farelo residual de milho sem e com a $\alpha$-amilase $(0,09 \mathrm{~g}$ para cada $30 \mathrm{~kg}$ da ração) para frangos de corte com 14 dias, foram determinados por Valadares et al. (2016). Os valores de EMAn do FRM com e sem enzima foram de 3241 e $3261 \mathrm{kcal} / \mathrm{kg}$, respectivamente. A adição da enzima melhorou o aproveitamento da energia do ingrediente, com aumento no coeficiente de metabolização da energia.
A suplementação de xilanase $(0$ e $1,0 \mathrm{~g} / \mathrm{kg})$ oriunda de Aspergillus niger foi avaliada sobre a digestibilidade dos nutrientes e o desempenho de frangos de corte alimentados com dietas à base de trigo. A enzima promoveu aumento na digestibilidade ileal da proteína bruta, do amido e dos polissacarídeos não amiláceos solúveis e insolúveis em 3,5\%, 9,3\%, $43,9 \%$ e $42,2 \%$, respectivamente. O consumo de ração não foi influenciado pela adição de xilanase, mas, aumentou $5,8 \%$ o ganho de peso e $5 \%$ a conversão alimentar aos 21 dias de idade. (Zhang et al., 2014).

Dietas com e sem amilase fúngicas (Aspergillus awamori) foram avaliadas por Morgado (2013) para frangos de corte, na fase pré-inicial e inicial, sobre as variáveis de desempenho e a metabolizabilidade dos nutrientes. Na fase de um a 7 dias, a adição de amilase aumentou o consumo de ração e piorou a conversão alimentar e o balanço de nitrogênio, já de 8 a 21 dias, não houve efeito nas variáveis de desempenho, mas piorou a metabolizabilidade da matéria seca, do extrato etéreo e o balanço de nitrogênio. $\mathrm{O}$ autor, não recomendou o uso da amilase para nenhuma das fases de criação estudada.

As enzimas adicionadas a dietas de aves apresentam resultados muitas vezes inconsistentes e conflitantes, devido a vários fatores, como, as diferenças no tipo de enzimas testadas, bem como no planejamento experimental e os nutrientes controle das dietas de controle negativas (Angel et al., 2011), dificultando a interpretação precisa de cada enzima.

\subsection{COMPLEXOS ENZIMÁTICOS}

A associação de enzimas pode ser usada satisfatoriamente com melhoria no aproveitamento dos nutrientes, no equilíbrio da microbiota bacteriana 
intestinal e com resultados positivos no desempenho das aves (Barbosa et al., 2012; Cowieson e Adeola, 2005), devido atuarem de maneira sinérgica (Meneghetti, 2013).

O efeito da eficiência enzimática foi avaliado em dietas com e sem redução de nutrientes versus adição ou não enzimática (fitase-100g/t e complexo enzimático-500g/t de amilase, xilanase e protease) sobre a digestibilidade ileal de frangos de corte de 22 e 43 dias. A redução dos nutrientes nas dietas promoveu diminuição na energia digestível e na digestibilidade da proteína, entretanto, a adição enzimática no controle negativo aumentou a energia digestível em ambas as idades (Barbosa et al., 2014).

O uso de complexo enzimático (fitase, protease, xilanase, $\beta$-glucanase, celulase, amilase e pectinase) com níveis de 0; 100; 200; 300 e 400 g/ton em dietas à base de milho e de farelo de soja foram avaliados sobre os parâmetros de desempenho, de rendimento de carcaça e de qualidade da carne de frangos de corte. A inclusão do complexo enzimático não influenciou o desempenho, $\mathrm{o}$ rendimento de carcaça e a qualidade da carne. No entanto, os níveis de $200 \mathrm{~g} /$ ton aumentou o rendimento de peito e das asas aos 42 dias (Dalólio et al., 2016).

A suplementação de xilanase e glucanase foi avaliada por Cowieson (2010) sobre as características de desempenho para frangos de corte em dietas à base de milho e farelo de soja. O uso de xilanase e glucanase em conjunto promoveu efeito superior ao das enzimas separadamente, mas inferior à soma dos seus efeitos individuais, sendo o melhor desempenho obtido com combinação de xilanase (16000 FTU/kg) e glucanase (30000 FTU/kg).

Nunes et al. (2015) avaliaram o uso de complexos enzimáticos em dietas de controle positivo e negativo sobre o desempenho e características de carcaça de frangos de corte. $\mathrm{Na}$ fase inicial, as aves suplementadas com complexo enzimático promoveram ganho de peso e conversão alimentar semelhante as que receberam dieta de controle positivo. Na fase final, o ganho de peso e conversão alimentar foi melhor com uso dos complexos e não afetou o rendimento de carcaça e cortes nobres.

Dietas à base de sorgo ou trigo contendo protease, xilanase e $\beta$-glucanase exógenas foram testadas sobre a metabolizabilidade dos nutrientes e desempenho de frangos de corte. A retenção de nitrogênio das aves aumentou, assim como o aproveitamento de nutrientes da dieta, $1,2 \%$ para a matéria seca, 2,6\% em proteína bruta e 2,0\% de energia bruta e com melhoria na conversão alimentar nas primeiras semanas de idade (Selle et al., 2010).

Pesquisas rotineiramente são realizadas e avaliaram os efeitos do uso de complexos enzimáticos na alimentação de aves, porém poucos especificaram a origem das enzimas (Quadro 2). 
Quadro 2. Pesquisas desenvolvidas e resultados obtidos com o uso de complexos enzimáticos para aves

\begin{tabular}{|c|c|c|c|}
\hline ARTIGO & TRATAMENTOS & ENZIMAS & RESULTADOS \\
\hline $\begin{array}{l}\text { Moraes et al. } \\
(2015)\end{array}$ & $\begin{array}{l}\text { Dietas contendo } 10 \% \text { de farelo de arroz } \\
\text { desengordurado: controle positivo e duas } \\
\text { dietas com redução de nutriente com ou } \\
\text { sem a adição de complexo enzimático } \\
(200 \mathrm{~g} / \mathrm{ton})\end{array}$ & $\begin{array}{l}\text { Fitase, protease, xilanase, } \beta \text {-glucanase, } \\
\text { celulase, pectinase, protease e amilase } \\
\text { (oriundas do Aspergillus niger) }\end{array}$ & $\begin{array}{l}\text { O uso do CE melhora a retenção de } \mathrm{P} \text { e a mineralização óssea, todavia, } \\
\text { não tem efeito positivo sobre o desempenho e ensaio metabólico de } \\
\text { frangos de corte alimentados com dieta controle ou redução de } \\
\text { nutrientes. A dieta controle proporcionou as aves melhor desempenho. }\end{array}$ \\
\hline $\begin{array}{l}\text { Sousa et al. } \\
(2014)\end{array}$ & $\begin{array}{l}0 \text { e } 20 \% \text { de Bagaço de mandioca, com e } \\
\text { sem complexo enzimático }(\mathrm{CE})\end{array}$ & $\begin{array}{l}\text { Fitase, protease, xilanase, } \beta \text {-glucanase, } \\
\text { celulase, amilase e pectinase (oriundas de } \\
\text { Aspergillus niger) }\end{array}$ & $\begin{array}{l}\text { A inclusão de CE de } 1 \text { a } 21 \text { dias melhorou em } 3,03 \% \text { o ganho de peso e } \\
3,19 \% \text { a conversão alimentar, independente do uso do bagaço de } \\
\text { mandioca e não apresentou efeito na fase de } 22 \text { a } 40 \text { dias }\end{array}$ \\
\hline $\begin{array}{l}\text { Freitas et al. } \\
(2016)\end{array}$ & $\begin{array}{l}\text { Ração controle e ração com adição do } \\
\text { complexo enzimático }(120 \mathrm{~mL} / \mathrm{kg})\end{array}$ & $\begin{array}{l}\text { Complexo enzimático oriundo de } \\
\text { Aspergillus wamori }\end{array}$ & $\begin{array}{l}\text { Na fase de } 1 \text { a } 21 \text { dias, a suplementação com complexo enzimático } \\
\text { aumentou o consumo de ração em } 10,97 \% \text {, o ganho de peso em } 4,05 \% \text {, } \\
\text { o peso final em } 2,03 \% \text {, porém, piorou a conversão alimentar em } 7,39 \text { e } \\
\text { de } 21 \text { a } 49 \text { dias não houve alteração nos parâmetros zootécnicos das } \\
\text { aves. }\end{array}$ \\
\hline $\begin{array}{l}\text { Leite et al. } \\
(2012)\end{array}$ & 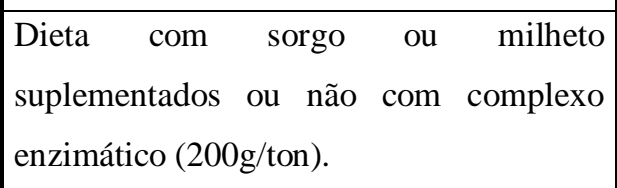 & $\begin{array}{l}\text { Amilase, pectinase, betaglucanase, } \\
\text { pentosanase, celulase, protease e fitase }\end{array}$ & $\begin{array}{l}\text { A suplementação enzimática para milheto ou sorgo não afetou a } \\
\text { microbiota intestinal e as variáveis de desempenho, no período de } 14 \text { e } \\
28 \text { dias e um a } 42 \text { dias, respectivamente. }\end{array}$ \\
\hline $\begin{array}{l}\text { Barbosa et al. } \\
(2012)\end{array}$ & $\begin{array}{l}\text { Duas dietas controle (positivo e negativo) } \\
\text { versus adição ou não enzimática }\end{array}$ & $\begin{array}{l}\text { Fitase }(100 \mathrm{~g} / \mathrm{t}) \text { e complexo enzimático de } \\
\text { amilase, xilanase e protease } \\
(500 \mathrm{~g} / \mathrm{t}) .\end{array}$ & $\begin{array}{l}\text { A adição de enzimas exógenas em dieta com redução nutricional } \\
\text { proporciona consumo de ração, peso vivo médio e ganho de peso } \\
\text { similar a dieta com níveis nutricionais adequados. }\end{array}$ \\
\hline $\begin{array}{l}\text { Cardoso et al. } \\
(2011)\end{array}$ & $\begin{array}{l}\text { Controle positivo; controle negativo, dieta } \\
\text { com amilase exógena e dieta com } \alpha \text { - } \\
\text { amilase e complexo enzimático }\end{array}$ & $\begin{array}{l}\alpha \text {-amilase e complexo enzimático }(\alpha- \\
\text { galactosidase, galactomananase, xilanase } \\
\text { e } \beta \text {-glucanase })\end{array}$ & $\begin{array}{l}\text { A utilização de complexo enzimático associado à enzima exógena } \alpha \text { - } \\
\text { amilase piora o desempenho, sem alterar o rendimento de carcaça e de } \\
\text { seus cortes e não altera o custo com a alimentação. }\end{array}$ \\
\hline
\end{tabular}


A mistura das enzimas nos complexos multienzimáticos podem promover respostas variáveis, pois são oriundas de diferentes microorganismos e não se conhece bem suas interelações e a atuação no organismo animal nas distintas fases de produção (Marques, 2007), tais como, fatores que influenciam no trato gastrointestinal: taxa de passagem, temperatura corporal das aves, $\mathrm{pH}$, comprimento do trato gastrointestinal, concentração do produto em razão da hidrólise da enzima e concentração das enzimas endógenas, além dos diferentes tipos de ingredientes utilizados nas dietas (Acomovic e Mccleary, 1996).

A maioria dos experimentos avaliou o uso das enzimas em dietas a base de milho e farelo de soja, fazendo-se necessário testar a inclusão desses aditivos em dietas com uso de alimentos alternativos de expressão regional, visando melhorar o aproveitamento dos nutrientes pelas aves e reduzir o custo de produção.

\section{CONSIDERAÇÕES FINAIS}

A demanda por alimentos balanceados e o alto custo da alimentação animal são fatores que têm incentivado os pesquisadores à busca por alimentos alternativos, principalmente os substitutos energéticos e proteicos do milho e do farelo de soja, todavia, esses ingredientes apresentam elevados teores de fibra que podem diminuir o aproveitamento dos nutrientes.

A utilização de enzimas fúngicas exógenas às dietas das aves podem reduzir os efeitos negativos dos fatores antinutricionais, todavia, torna-se necessário avaliar o uso dos aditivos com ingredientes de expressão regional, para que possam resultar em melhorias nos processos digestivos e, consequentemente, ao desempenho zootécnico das aves.

Diante do exposto, evidenciou-se a importância do uso desses aditivos zootécnicos digestivos, com benefícios na nutrição das aves, podendo ser empregado em escala comercial e, por conseguinte, reduzir os custos de produção da cadeia avícola.

Todos os autores declararam não haver qualquer potencial conflito de interesses referente a este artigo.

\section{REFERÊNCIAS BIBLIOGRÁFICAS}

ACOMOVIC, T.; MC CLEARY, B.V. Optimising the response.Feed Mix, v.4, n.4, p.14-19,1996.

AGUIAR, C.L.; MENEZES, T.J.B. Produção de celulases e xilanases por Aspergillus niger IZ-9 usando fermentação submersa sobre bagaço de canade-açúcar. Boletim do Centro de Pesquisa e

Processamento de Alimentos, v.18, n.1, p. 57-70, 2000.

ANGEL, C.R.; SAYLOR, W.; VIEIRA, S.L.; WARD, $\mathrm{N}$. Effects of a monocomponent protease on performance and protein utilization in 7- to 22-dayold broiler chickens. Poultry Science, v. 90, p. 22812286, 2011.

BARBOSA, N. A.A.; BONATO, M. A.; SAKOMURA, N. K.; DOURADO, L. R. B.; FERNANDES, J.B. K.; KAWAUCHI, I. M. Digestibilidade ileal de frangos de corte alimentados com dietas suplementadas com enzimas exógenas.

ComunicataScientiae, v. 5, n. 4, p. 361-369, 2014.

BARBOSA, N.A.A.; SAKOMURA, N.K.; BONATO, M.A.; HAUSCHILD, L.; OVIEDO-RONDON, E.

Enzimas exógenas em dietas de frangos de corte: desempenho. Ciência Rural, v.42, n.8, 2012.

BARBOSA, N.A.A.; SAKOMURA, N.K.; FERNANDES, J.B.K.; DOURADO, L.R.B. Enzimas exógenas no desempenho e na digestibilidade ileal de nutrientes em frangos de corte. Pesquisa

Agropecuária Brasileira, v.43, n.6, p.755-762, 2008. 
BELLAVER, C. Aspectos técnicos e econômicos da utilização de sub-produtos de origem animal na alimentação de frangos de corte. In: II SIMPÓSIO INTERNACIONAL ACAV/EMBRAPA -

NUTRIÇÃO DE AVES...2001, Concórdia-SC, 2001.

BRASIL. Ministério da Agricultura, Pecuária e Abastecimento. Instrução Normativa $n^{\circ} 13$, de 30 de novembro de 2004. Regulamento técnico sobre aditivos para produtosdestinados à alimentação animal. Diário Oficial da União. 01 de dezembro de 2004,Seção 3, p. 97.

BRITO, M. S.; OLIVEIRA, C. F. S.; SILVA, T. R. G.; LIMA, R. B.; MORAIS, S. N.; SILVA, J. H. V. Polissacarideos não amiláceos na nutrição de monogástricos - Revisão. Acta VeterinariaBrasilica, v.2, n.4, p.111-117, 2008.

CARDOSO, D.M.; MACIEL, M.P.; PASSOS, D.P.; SILVA, F.V.; REIS, S.T.; AIURA, F.S. Efeito do uso de complexo enzimático em rações para frangos de corte. Arquivos de Zootecnia, v.60, n.232, p.10531064, 2011.

CARDOSO JUNIOR, A.; RODRIGUES, P. B.; BERTECHINI, A. G.; FREITAS, R. R. F.; LIMA, R. R.; LIMA, G. F. R. Levels of available phosphorus and calcium for broilers from 8 to 35 days of age fed rations containing phytase. Revista Brasileira de Zootecnia, v.39, n.6, p.1237-1245, 2010.

CARNEIRO, M.I.F.; SAKOMURA, N.K.; KAWAUCHI, I.M.; SILVA, E.P.; ARAUJO, J. A.; FERNANDES, J.B.K.; GOMES FILHO, J.S.

Avaliação do mesocarpo de babaçu (Orbignyassp) na alimentação de frangos de corte. ArsVeterinaria, v.29, n.3, 175-182, 2013.

CLASSEN, H.L. Cereal grain starch and exogenous enzymes in poultry diets.Animal Feed Science Technology, v. 62, p. 21-27. 1996.

CAMPESTRINI, E.; SILVA, V.T.M.; APPELT, M.D. Utilização de enzimas na alimentação animal.

RevistaEletrônicaNutritime, v.2, p:254-267, 2005.

CĂPRIŢĂ, R.; CĂPRIŢĂ, A.; JULEAN, C.

Biochemical Aspects of Non-Starch

Polysaccharides.Animal Science and

Biotechnologies, v. 43, n.1, 2010.

COLLINS, T.; GERDAY, C.; FELLER, G.

Xylanases, xylanase families and extremophilicxylanases. FEMS microbiology reviews, v. 29, n. 1, p. 3-23, 2005.

COWIESON, A. J.; BEDFORD, M.R.;

RAVINDRAN, V. Interactions between xylanase and glucanase in maize-soy-based diets for broilers.British Poultry Science, v.51, n. 2, p.246-57, 2010.

COWIESON, A.J.; ADEOLA, O. Carbohydrases, protease and phytase have an additive beneficial effect in nutritionally marginal diets for broiler chicks.

Poultry Science, v.84, p.1860-1867, 2005.

COWIESON, A.J.; HRUBY, M.; PIERSON, E.E.M. Evolving enzyme technology: Impact on commercial poultry nutrition. Nutrition Research - Reviews, v.19, p. 90-103, 2006.

COWIESON, A.J. Strategic selection of exogenous enzymes for corn/soy-based poultry diets.Japan Poultry Science Association, v.47, p.1-7, 2010.

CHOCT, M. Feed Non-Starch Polysaccharides: Chemical Structures and Nutritional Significance.FeedMillingInternational, JuneIssue, p.13-26, 1997.

CONTE, A.J.; TEXEIRA, A.S.; FIALHO, E.T.; SCHOULTEN, N.A.; BERTECHINI, A.G. Efeito da fitase e xilanase sobre o desempenho e as características ósseas de frangos de corte alimentados com dietas contendo farelo de arroz. Revista Brasileira de Zootecnia, v. 32, n. 5, p. 1147-1156, 2003.

DOURADO, L.R.B.; BARBOSA, N.A.A.; SAKOMURA, N.K. Enzimas na nutrição de monogástricos. In: SAKOMURA, N.K.; SILVA, J.H.V. da.; COSTA, F.G.P.; FERNANDES, J.B.K.; HAUSCHILD, L. Nutrição de monogástricos. Jaboticabal: Funep, 2014. p. 466-484.

DESSIMONI, G. V. Planos nutricionais com suplementação de protease de frango de corte. 2011. 49f. Dissertação (Magister Scientiae)Universidade Federal dos Vales do Jequitinhonha e Mucuri, 2011.

DALÓLIO, F.S.; MOREIRA, J.; VAZ, D.P.; ALBINO, L.F.T.; VALADARES, L.R.; PIRES, A.V.; PINHEIRO, S.R.F. Exogenous enzymes in diets for broilers. Revista Brasileira de Saúde e Produção Animal, v.17, n.2, p.149-161, 2016. 
ELKHALIL, E.A.I.; MANNER, K.; BORRISS, R.; SIMON, O.In vitro and in vivo characteristics of bacterial phytases and their efficacy in broiler chickens.British Poultry Science, v. 48, n.1, p. 6470, 2007.

FIORDA, F.A.; JUNIOR, M.S.S.; SILVA, F.A.da S.; SOUTO, L.R.F.; GROSSMANN, M.V.E.Farinha de bagaço de mandioca: aproveitamento de subproduto e comparação com fécula de mandioca. Pesquisa Agropecuária Tropical, v. 43, n. 4, p. 408-416, 2013.

FIREMAN, F.A.T; FIREMAN, A.K.B.A.T. Enzimas na alimentação de suínos. Ciência Rural, v.28, p.173178, 1998.

FREITAS, P.V.D.X. de.; ALMEIDA, E.M.de.; MORGADO, H.S.; CYSNEIROS, C. dos S. S.; SANTOS, J. S. Complexo enzimático em dieta para frangos Label Rouge. Revista Eletrônica Nutritime, v. 13, n.3, 2016.

GERHARDT, G. Utilização de carboidrases em dietas à base de milho e farelo de soja para frangos de corte. 2013. 34f. Trabalho de conclusão de curso (Graduação em medicina veterinária) - Universidade Federal do Rio Grande do Sul, 2013.

GOMES, E.; GUEZ, M.A.U.; MARTIN, N.; SILVA, R. Enzimas termoestáveis: fontes, produção e aplicação industrial. Química Nova, v. 30, n. 1, p. 136-145, 2007.

GOMIDE, E.M.; RODRIGUES, P.B.; BETERCHINI, A.G.; FREITAS, T.F.; FASSANI, E.J.; REIS, M.P.; RODRIGUES, N.E.B.; ALMEIDA, E.C. Rações com níveis reduzidos de proteína bruta, cálcio e fósforo com fitase e aminoácidos para frangos de corte.

Revista Brasileira de Zootecnia, v. 40, n.11, p. 2405-2414, 2011a.

GOMIDE, E.M.; RODRIGUES, P.B.; ZANGERONIMO, M.G.; BETERCHINI, A.G.; DOS SANTOS, L. M.; ALVARENGA, R.R. Nitrogen, calciumandphosphorus balance ofbroilersfed diets withphytaseandcrystallineaminoacid. Ciência e Agrotecnologia, Lavras, v. 35, n.3, p. 591-597, maio/jun., 2011b.

GONÇALVES, A. Z. L. Produção de $\boldsymbol{\alpha}$-amilase e glucoamilase termoestávelpelo fungo termofílicoThermomyceslanuginosus TO-03 por fermentação submersa e em estado sólido e caracterização das enzimas. 2006. 90f. Dissertação
(Mestre em Ciências Biológicas) - Universidade Estadual Paulista "Júlio de Mesquita Filho", 2006.

HOLANDA, M.A.C. de.; HOLANDA, M.C.R. de.; VIGODERES, R.B.; DUTRA JUNIOR, W.M.; ALBINO, L.F.T. Desempenho de frangos caipiras alimentados com farelo integral de mandioca. Revista Brasileira de Saúde e Produção Animal, v.16, n.1, p.106-117, 2015.

ISAKSEN, M.F.; COIESON, A.J.; KRAGH, K.M. Starch-and protein degrading enzymes: biochemistry, enzymology and characteristics relevant to animal feed use. In: BEDFORD, M.R.; PARTRIGDE, G.G. Enzymes in farm animal nutrition. 2 ed. London: UK, 2011. p. 85-94.

IRSHAD, M.; ANWAR, Z.; AFROZ, A.

Characterization of Exo 1, 4-ßglucanase produced from TrichodermaViridi through solid-state bioprocessing of orange peel waste. Advances in Bioscience and Biotechnology, v. 3, p. 580-584, 2012.

JERACI, J.L.; VAN SOEST, P.J. Improved methods for analysis and biological characterization of fiber.Advances in experimental medicine and biology, v.270, p.245-263, 1990.

KORNEGAY, E.T. Digestion of phosphorus and other nutrients: the role of phytases and factors influencing their activity. In: BEDFORD, M.R.; PARTRIDGE, G.G. Enzymes in farm animal nutrition.Wallingford: CAB International, 2001. p.237-271.

KILIKIAN, B.V.; PESSOA JR. A. Purificação de produtos biotecnológicos. In: SCHMIDEL W.; LIMA, U. de A.; AQUARONE, E.; BORZANI, W.

Biotecnologia industrial: engenharia bioquímica. 1 . Ed. v. 2. São Paulo: Edgard Blücher, 2001. p. 493521.

LEITE, P.R.S.C.; LEANDRO, N.S.M.;

STRINGHINI, J.H.; SOUZA, E.S.; CAFÉ, M.B.; CARVALHO, F.B.; ANDRADE, M.A. Microbiota intestinal e desempenho de frangos alimentados com rações elaboradas com sorgo ou milheto e complexo enzimático. Arquivo Brasileiro de Medicina Veterinária e Zootecnia, v.64, n.6, p.1673-1681, 2012.

LIMA, M. R. de.; SILVA, J. H. V. da.; ARAUJO, J. A. de.; LIMA, C. B.; OLIVEIRA, E. R. A. de. 
Enzimas exógenas na alimentação de aves. Acta

VeterinariaBrasilica, v.1, n.4, p.99-110, 2007

LOPES, F.P. Otimização da produção de xilanase por levedura silvestre. 2010. 89f. Dissertação (Mestre em Engenharia de Alimentos) - Faculdade de Engenharia de Alimentos, Universidade Estadual de Campinas, 2010.

MARQUES, S.F.F. Biotecnologia enzimática: produção de complexo multienzimático de Trichodermaharzianume sua aplicação na alimentação de frangos de corte. 2007. $92 \mathrm{f}$. Dissertação (Mestre em Ciência Animal) Universidade Federal do Goiás, 2007.

MARTINS, V. G.; KALIL, S.J.; COSTA, J.A.V. Coprodução de lipase e biossurfactante em estado sólido para utilização em biorremediação de óleos vegetais e hidrocarbonetos. Química Nova, v.31, n.8, 2008.

MATIAS, C.F.Q.; ROCHA, J.S.R.; POMPEU, M.A.; BAIÃO, R.C.; BAIÃO, N.C.; LARA, L.J.C.; CLÍMACO, W.L.S.; PEREIRA, L.F.P.; CALDAS, E.O.; TEIXEIRA, M.P.F.; CARDEAL, P.C. Efeito da protease sobre o coeficiente de metabolizabilidade dos nutrientes em frangos de corte. Arquivo Brasileiro de Medicina Veterinária e Zootecnia, v.67, n.2, p.492498, 2015.

MENDES, A.R.A. Suplementação com Xilanase de Regimes Alimentaresà base de Milho e Soja para Frangos de Carne. 2015. 78f. Dissertação (Mestre em Engenharia Zootécnica - Produção Animal) Instituto Superior de Agrônomia, Universidade de Lisboa, 2015.

MENEZES, C.R.de.; BARRETO, A.R.

Biodegradação de resíduos lignocelulósicos por fungos basidiomicetos: Caracterização dos resíduos e estudo do complexoenzimático fúngico. Revista do Centro de Ciências Naturais e Exatas. Revista Eletrônica em Gestão, Educação e Tecnologia Ambiental, v. 19, n. 2, p. 1365-1391, 2015.

MESSIAS, J.M.; COSTA, B.Z.; LIMA, V.M.G. de.; GIESE, E.C.; DEKKER, R.F.H.; BARBOSA, A. de M. Lipases microbianas: Produção, propriedades e aplicaçõesBiotecnológicas. Semina: Ciências Exatas e Tecnológicas, v. 32, n. 2, p. 213-234, 2011.

MOURINHO, I. Avaliação nutricional da casca de soja com ou sem adição de complexo enzimático para leitões na fase inicial. 2006. 55f. Dissertação
(Mestre em Zootecnia) - Universidade Estadual De Maringá, Maringá, 2006.

MORAES, M.L.; LEDUR, V.S.; KESSLER, A.M.; MACHADO, P.H.M.; DELLS, M.P.; RIBEIRO, A.M.L. Effect of an Enzyme Blend on the Performance, Diet Metabolizability, Phosphorous Retention, and Bone Mineralization of Broilers Fed Diets Containing Defatted Rice Bran. Revista Brasileira de Ciência Avícola, v.17, n.2, 2015.

MORALES, P.; MADARRO, A.; FLORS, A.; SENDRA, J.M.; PEREZ-GONCALVES, J.A.

Purificationandcharacterizationof a

xylanaseandanarabinofuranosidasefrom Bacillus

polymyxa. Enzymeand Microbial Technology, v.17, p.424-429, 1995.

MORGADO, H. S. Produção e caracterização de amilase do fungo Aspergillus awamori e sua utilização em dietas para frangos de corte. 2013. 110f. Tese (Doutor em Ciência Animal) -

Universidade Federal do Goiás, Goiania-GO, 2013.

MARZZOCO, A.; TORRES, B. B. Bioquímica básica. 3. ed. Rio de Janeiro: Editora Guanabara Koogan, 2007.

MENEGHETTI, C. Associação de enzimas em rações para frangos de corte. 2013. 96f. Tese (Doutorado em Zootecnia) - Universidade Federal de Lavras, 2013.

MINAFRA, C.S. Produção e suplementação $\operatorname{com} \alpha-$ amilase de Cryptococcus flavus e Aspergillus Níger HM2003 na dieta de frangos de corte de um a 21 dias de idade. 2007. $141 \mathrm{f}$. Tese (Doutorado em Bioquímica Agrícola) - Universidade Federal de Viçosa, Viçosa, 2007.

NELSON, D. L.; COX, M. M. Princípios de bioquímica de Lehninger. 6. ed. Porto Alegre: Artmed, 2014, 1298p.

NUNES, J.O.; ABREUL, R.D.; BRITO, J.A.G.; SILVA, R.F.; OLIVEIRA, L.S.; JESUS, N.A. Enzyme Supplementation of Broiler Feeds with Reduced Mineral and Energy Levels. Revista Brasileira de Ciência Avícola, v.17, Oct./Dec, 2015.

OLIVEIRA, I. M. M. de. Caracterização nutricional do bagaço de mandioca e sua utilização na alimentação de frangos de crescimento lento. 2012. 73f. Dissertação (Mestre em Produção Animal) - 
Universidade Federal do Tocantins, Araguaína-TO, 2012.

OTT, R. P. Utilização de carbohidrases em dietas para frangos de corte. 2005. 83f. Dissertação (Mestre em Zootecnia) - Universidade Federal do Rio Grande do Sul, Faculdade de Agronomia; Porto Alegre, 2005.

PAZ, F.R.; MARTINEZ, J.P.; MONTI, R. Produção e caracterização da xilanase de Aspergillussp.

Alimentos e Nutrição Araraquara, v. 25, n.1, 2014.

PEIXOTO-NOGUEIRA, S.C.; BERTPÁGLIA, L.; LEANDRO, G. da S.; REIS, R.A.; JORGE, J.A.; POLIZELI, M. de L.T. de M. Estabilidade xilanásica no rúmen e digestibilidade in vitro de volumosos tratados com extrato enzimático de Aspergillus niveus. Revista Brasileira de Higiene e Sanidade Animal, v.7, n.1, p. 46-60, 2013.

PEREIRA, A. A.; JUNQUEIRA, O.M.; ALVA, J.C.R.; SGAVIOLI, S.; PRAES, M.F.F.M.; GRIEP JUNIOR, D.N. Utilização de rações de poedeiras comerciais formuladas com fitase e níveis de proteína bruta sobre a excreção de fósforo, nitrogênio e cálcio. ARS Veterinária, Jaboticabal, SP, v. 26, n.3, 178183, 2010.

PEREIRA, R.; MENTEN, J.F.M.; ROMANO, G.G.; SILVA, C.L.S.; ZAVARIZE, K.C.; BARBOSA, N.A.A. Eficiência de uma fitase bacteriana na liberação de fósforo fítico em dietas de frangos de corte. Arquivo Brasileiro de Medicina Veterinária e Zootecnia, v. 64, n.1, p. 137-144, 2012.

PESSOA, G.B.S. Avaliação de complexo enzimático em dietas de frangos de corte. 2010. $75 f$.

Dissertação (Magister Scientiae) - Universidade Federal de Viçosa. 2010.

POLYCARPO, G. do V. Complexo multienzimático e fontes lipídicas em rações para frangos de corte. 2011. 70f. Dissertação (Mestre em Zootecnia) Universidade Estadual Paulista, Faculdade de Medicina Veterinária e Zootecnia, Botucatu-SP, 2011.

SANTOS, J.F.dos.; GRANGEIRO, J.I.T.

Desempenho de aves caipira de corte alimentadas com mandioca e palma forrageira enriquecidas com levedura.Tecnologia \& Ciência Agropecuária, João Pessoa, v.6, n.2, p.49-54, 2012.

SANTOS, L.F. dos.; ISHII, P.L. Xilanases: Principais Metodologias e
ParâmetrosCinéticos.JournalofBiotechnologyandBio diversity - Review, v. 2, n. 2, p.7-15, 2011.

SANTOS NETA, E. R. Avaliação de subprodutos do babaçu (Palmaeorbignyamartiana) na alimentação de frangos de corte. 2010. 59f. Dissertação (Mestre em Ciência Animal Tropical) Escola de Medicina Veterinária e Zootecnia, Universidade Federal do Tocantins, Araguaína, 2010.

SELLE, P. H. et al. Impact of exogenous enzymes in sorghum-or wheat-based broiler

diets on nutrient utilization and growth performance.

International Journal of Poultry Science, v.9, n.1, p.53-58, 2010.

SILVA, R. F. da.Avaliação nutricional da torta de babaçu e sua utilização em dietas para frangos de corte labelrouge. 2009. 83f. Dissertação (Mestre em Produção Animal) - Universidade Federal de Goiás, Goiânia-GO, 2009.

SILVA, E. G. da. Torta de dendê na alimentação de frangos de crescimento lento criados no sistema caipira. 2011. 53f. Dissertação (Mestre em Produção Animal) - Universidade Federal do Tocantins, Araguaína-TO, 2011.

SILVA, H.G.de O.; PIRES, A.J.V.; NETO, P.A. da C.; CARVALHO, G.G.P. de; VELOSO, C.M.; SILVA, F.F.da. Digestibilidade de dietas contendo silagem de capim-elefante amonizado e farelo de cacau ou torta de dendê em ovinos. Revista Brasileira de Zootecnia, Viçosa, v.36, n.2, p.499-506, 2007.

SILVA, D.J.; QUEIROZ, A.C. Análise de alimentos, métodos químicos e biológicos. 3. ed. Viçosa: UFV, 2006.

SOUSA, J. P. L. Fitase (Escherichia coli) em dietas com correções nutricionais para frangos de corte. 2013. 96f. Tese (Doutora em Ciência Animal) Universidade Federal do Tocantins, 2013.

SOUSA, J.P.L.; RODRIGUES, K.F.; ALBINO, L.F.T.; VAZ, R.G.M.V.; SILVA, G.F.; SIQUEIRA, J.C.; SANTOS NETA, E.R.; PARENTE, I.P.; AMORIM, A.F.; SILVA, M.C. da. Bagaço de mandioca com ou sem complexo enzimático em dietas de frangos de corte. Archivos de Zootecnia, v.63, n.244, p.657-664, 2014.

STEFANELLO, C.; VIEIRA, S.L.; CARVALHO, P.S.; SORBARA, J.O.B.; COWIESON, A.J. Energy and nutrient utilization of broiler chickens fed corn- 
soybean meal and corn-based diets supplemented with xylanase. Poultry Science, v.0, p.1-7, 2016.

VALADARES, C.G.; SANTOS, J.S.; LUDKE, M.C.M.M.; LUDKE, J.V.; SILVA, J.C.N.S.; PEREIRA, P.S. Determinação da energia metabolizável do farelo residual do milho com e sem enzima em dietas para frangos de corte. Arquivo Brasileiro de Medicina Veterinária e Zootecnia, v.68, n.3, 2016.

VANDER, A. J.; SHERMAN, J. H.; DOROTHY, L. S. Humanphysiology:

themechanismsofbodyfunction. 8. ed. New York: McGraw Hill, 2000. 800 p.
VASCONCELLOS, C.H.F.; FONTES, D.O.; LARA, L.J.C.; VIDAL, T.Z.B.; SILVA, M.A. SILLVA, P. C. Determinação da energia metabolizável e balanço de nitrogênio de dietas com diferentes teores de proteína bruta para frangos de corte. Arquivos Brasileira de Medicina Veterinária e Zootecnia, v. 63, n.3, p. 659-669, 2011.

ZHANG, L.; XU, J.; LEI, L.; JIANG, Y.; GAO, F.; ZHOU, G.H. Effects of Xylanase Supplementation on Growth Performance, Nutrient Digestibility and Nonstarch Polysaccharide Degradation in Different Sections of the Gastrointestinal Tract of Broilers Fed Wheat-based Diets. Asian-AustralasianJournalof Animal Sciences, v. 27, n.6, p. 855-861, 2014. 